\title{
Forthcoming Euroson Schools
}

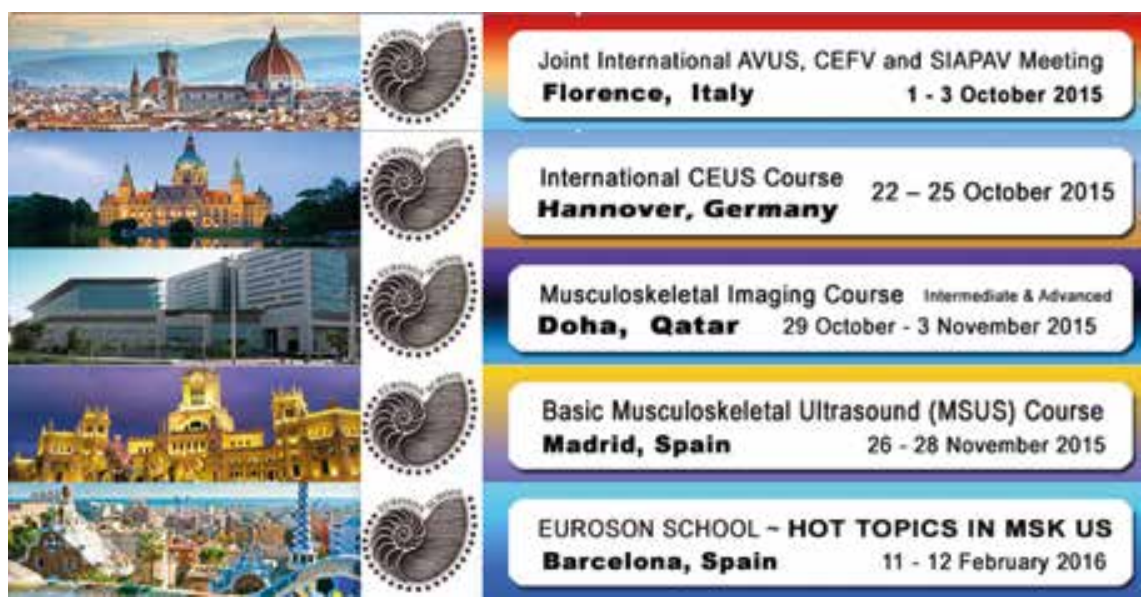

For all of the latest Euroson Schools please visit the dedicated EFSUMB page EUROSON 2016: www.ultrasound2016.org/en/ 